\title{
From Scratch
}

Sergio Kafejian

Faculdade Santa Marcelina | Brasil

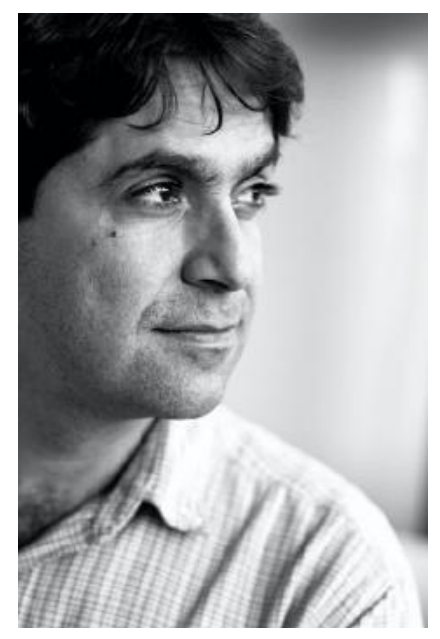

Kafejian has obtained his Masters from the Brunel University (London), PhD from UNESP and had developed a Postdoctoral Research at USP from 2016 to 2020. In 2017 has been researching as a Visiting Scholar at NYU Steinhardt. As a composer has won several composition prizes as Bourges International Electroacoustic Music Contest (1998 and 2008), Gilberto Mendes Contest for Orchestra (2008), FUNARTE Classical Composition Prize (2009 and 2015) and Funarte Prize for arts interactions (2008). Kafejian has been the artistic director of the Brazilian Contemporary ensemble Camerata Aberta from 2010 to 2015. During this period the ensemble has performed more than 40 concerts in Brasil and has performed in EUA (2010, 2011 and 2014), Belgic (2012), Holland (2012) and Portugal (2015). Kafejian is intensively involved in pedagogical projects related to contemporary music, contemporary improvisation and composition. Since 2001, has worked at Santa Marcelina College teaching composition, electroacoustic music and contemporary music.

\section{E-mail: kafejian@uol.com.br}

Website: https://soundcloud.com/sergio-kafejian

ORCID: https://orcid.org/0000-0001-5090-0187

Received on: August 29th, 2020. Approved on: September 18th, 2020. Available online on: December 15th, 2020. Guest editor: Dr. Humberto Amorim. Editor-in-chief: Dr. Felipe de Almeida Ribeiro. 
$\mathrm{W}$

ritten in 2017 for acoustic guitar and electronics From Scratch reflects several years of my research upon the classical guitar sound's possibilities. The sonorities used came out from exploring the instrument in different musical contexts and languages as free improvisation, jazz, Brazilian popular music and classical concert music ${ }^{1}$. From Scratch's main proposal is to integrate the vast sound range obtained by exploring traditional technics, extended technics, live processing and fixed media resources.

Structurally, the piece has three layers of materials that are constantly changing the interrelation they undertake. They are: (1) the acoustic sounds; (2) the fixed electroacoustic sounds; (3) the live electronics manipulations. The main challenge underlying the composition was to create an organic discourse even taking up a wide sort of guitar sonorities and electronic sounds.

The creation processes has been carried out in collaboration with the guitar player Dan Lippel, to whom the piece is dedicated, and has consisted of: (1) meetings to test and discuss extended technique possibilities; (2) a studio session at Dolan Studio in which several extended techniques sonorities have been recorded; (3) two meetings to test the notational system and the live electronics processing (4) rehearsal meetings; (5) live performance in a solo concert; (5) Recording of the piece at Oktaven Studio.

\section{Acoustic Music Materials}

Above and beyond using the traditional acoustic guitar sonorities, the idea of using different objects to pluck the guitar has been central in the composition process. After several tests, the following objects - with its related sound possibilities - have been chosen: (1) a small ruler allowing the player to create a wide sort of scratching sounds; (2) two knitting needles interleaved in the guitar strings; (3) guitar slide used to scratch the guitar scale. In addition to these objects, the piece makes use of extended techniques produced without external objects like: (1) percussive sounds obtained by hitting on the instrument's body, on the scale and on the strings; (2) nails scratching the strings; (3) muffed pizzicatos.

\footnotetext{
${ }^{1}$ The piece extends the research initiated with In Harmonica, a composition written for acoustic guitar and electronics in 2008 for the guitar player Daniel Murray.
} 


\section{Electroacoustic Music Materials}

The electroacoustic sounds are entirely derived from digital manipulations of the material recorded during the studio session. The resulting sonorities go from sounds bearing non-recognizable relations with acoustic guitar sonorities to natural acoustic guitar sonorities. These sounds have been used to: (1) create non-hierarchical dialogues with the player; (2) create soundscapes over which the acoustic guitar would blend, imitate or contrast; (3) offer new sound morphologies inspiring new instrumental gestures and new acoustic sound qualities.

Regarding the electroacoustic sonorities, we have decided to couple the traditional guitar sounds to the live electronics processing and to leave the sonorities coming from the extended technics without live processing. The reasons to reserve the live manipulations to be used with the traditional acoustic guitar techniques is firstly to give a particular sonic environment for each playing technic and secondly to create a sense of balance between the materials. Therefore, as far the sonority comes from the traditional sound repertoire, as more the live manipulations extend it.

Acknowledges: We would like to thank Fundação de Amparo à Pesquisa do Estado de São Paulo/FAPESP (São Paulo Research Foundation) for supporting the author's research: proc. No 2016/15484-1. 


\section{From Scratch(2017)}

Guitar and 4 channel Electronics

Sergio Kafejian 


\section{Instructions}

$\square \quad=$ to use a small ruler as a plectrum.

= to hit or to scracth with the hand.

Beyond the traditional notation staves there are a two system staves to write down some extended techniques. They use simbolic clefs representing tue guitar body's parts. Some passages use two staffs the upper one for the right hand and the lower one to the left hand. Nonetheless, the performer can ocasionally change the hands in case it would be more practical.

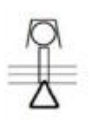

$=$ stylized representation of the guitar body; the triangle represents the head, the rectangle represents the scale and the circle represents the sound hole.

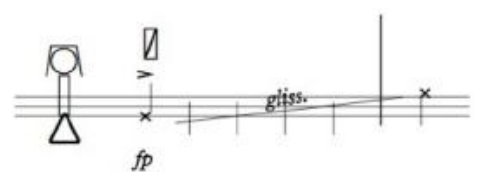

$f p$
$=$ to scratch the ruler on the strings from the begining of the scale (position 2 or 3 ) to a region close to the sound hole.

O = stylized representation of the guitar sound hole.

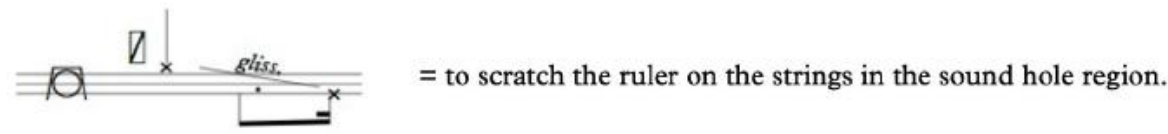

I $\quad=$ stylized representation of the guitar sound board.
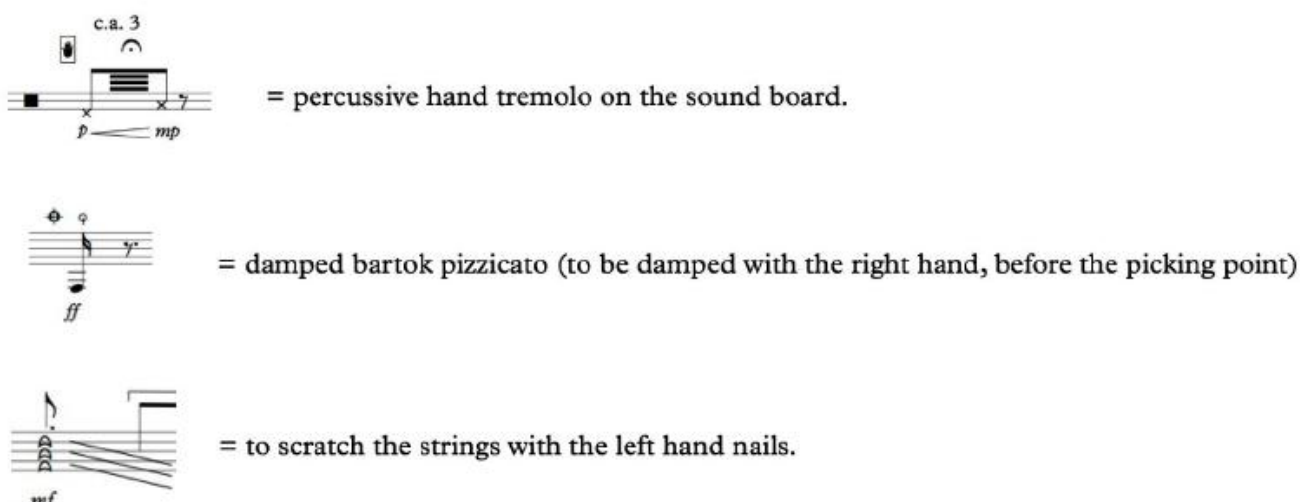

$m f$

The electronic clues to play the pre-recorded sound files are indicated by the red numbers above the staff. The continuos red lines indicated, when necessary, the sound file lenghts. 
From Scratch

To Dan Lippel

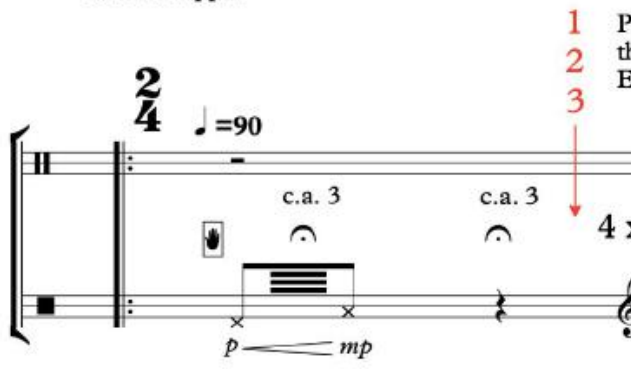

the 2 nd, 3 rd and 4 th repetition.

Each time with different time lapses.
Play the bang after

4 the 2 nd repetition and attack next measure after 2 secs.
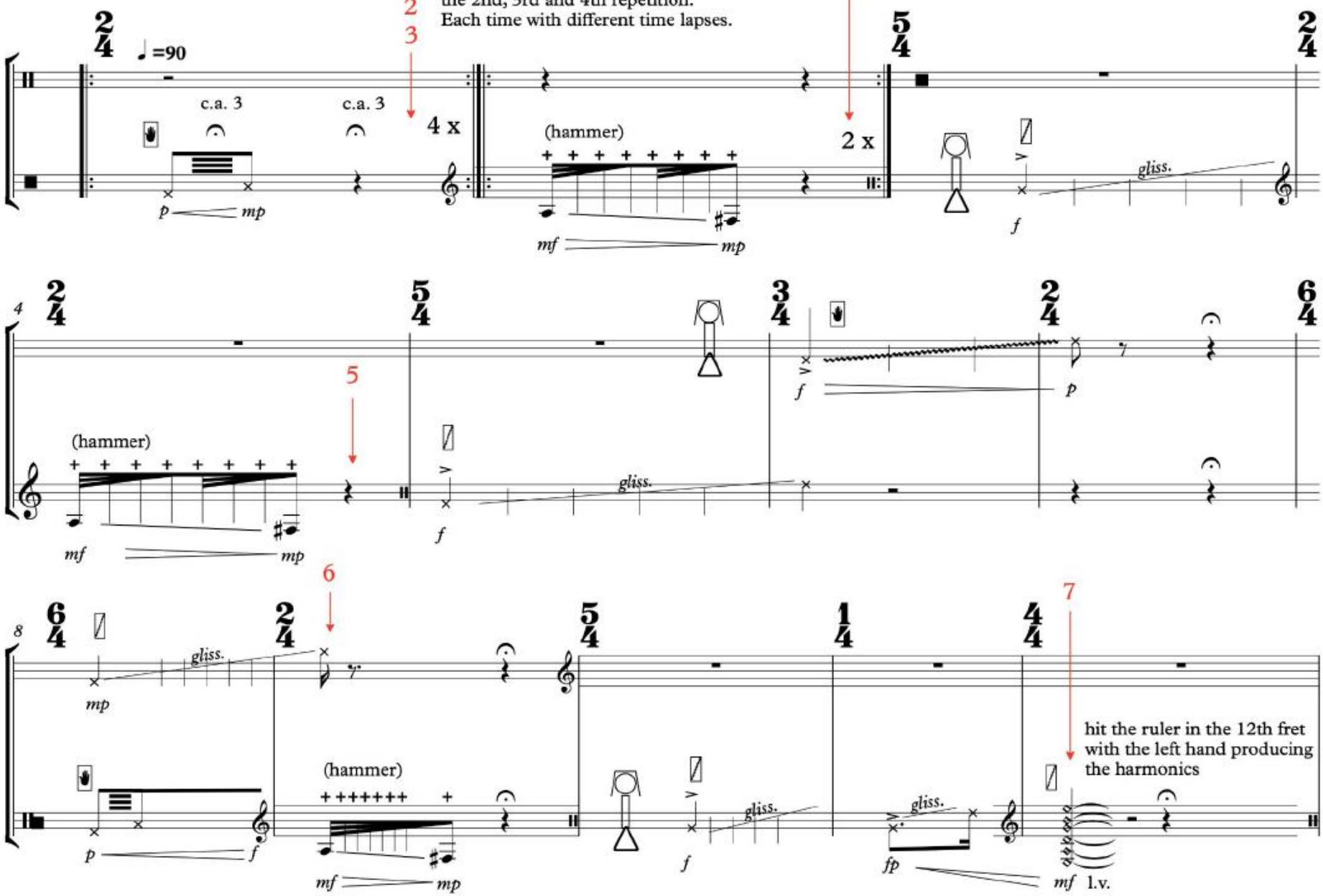

.$=80$

rit. -
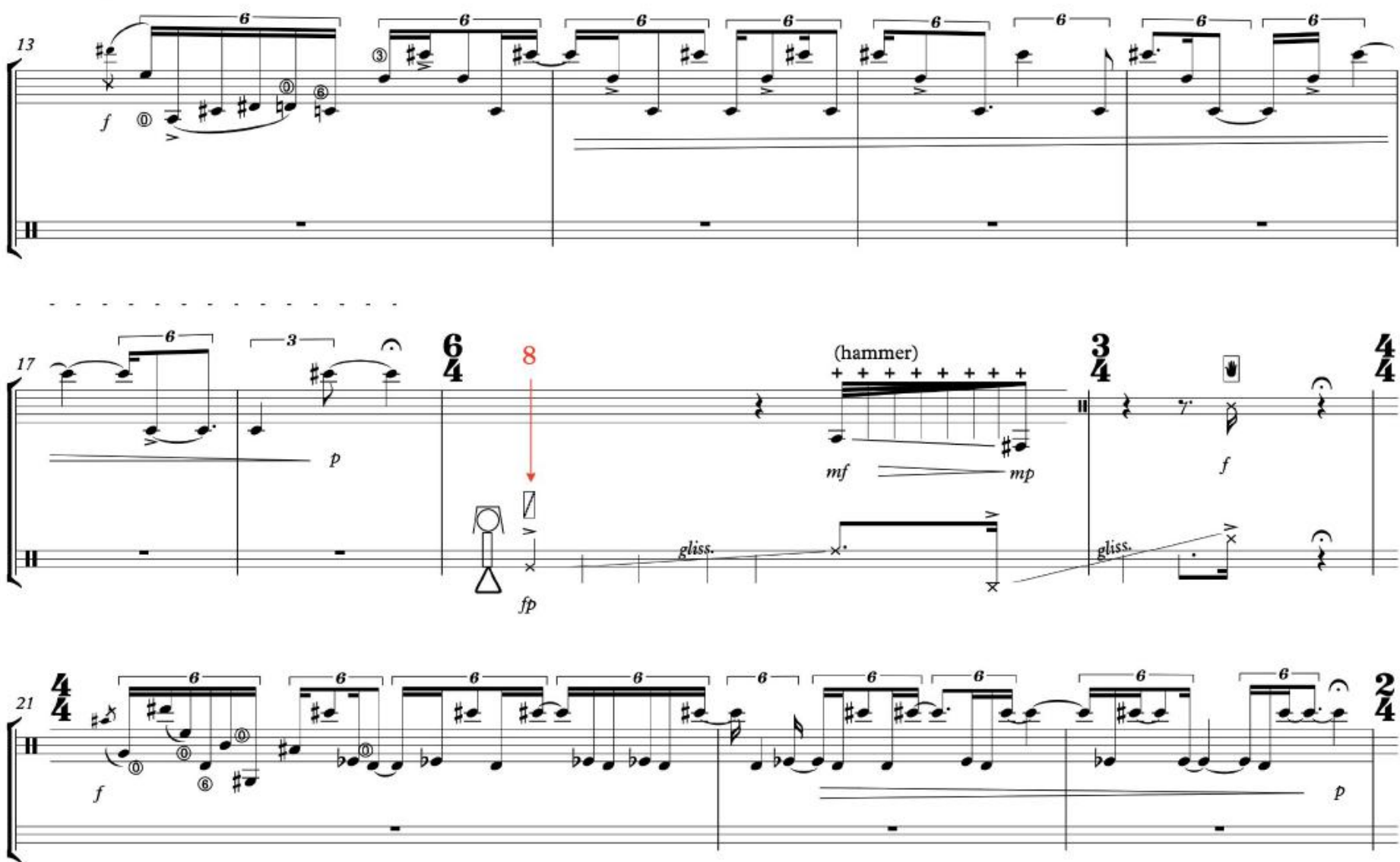

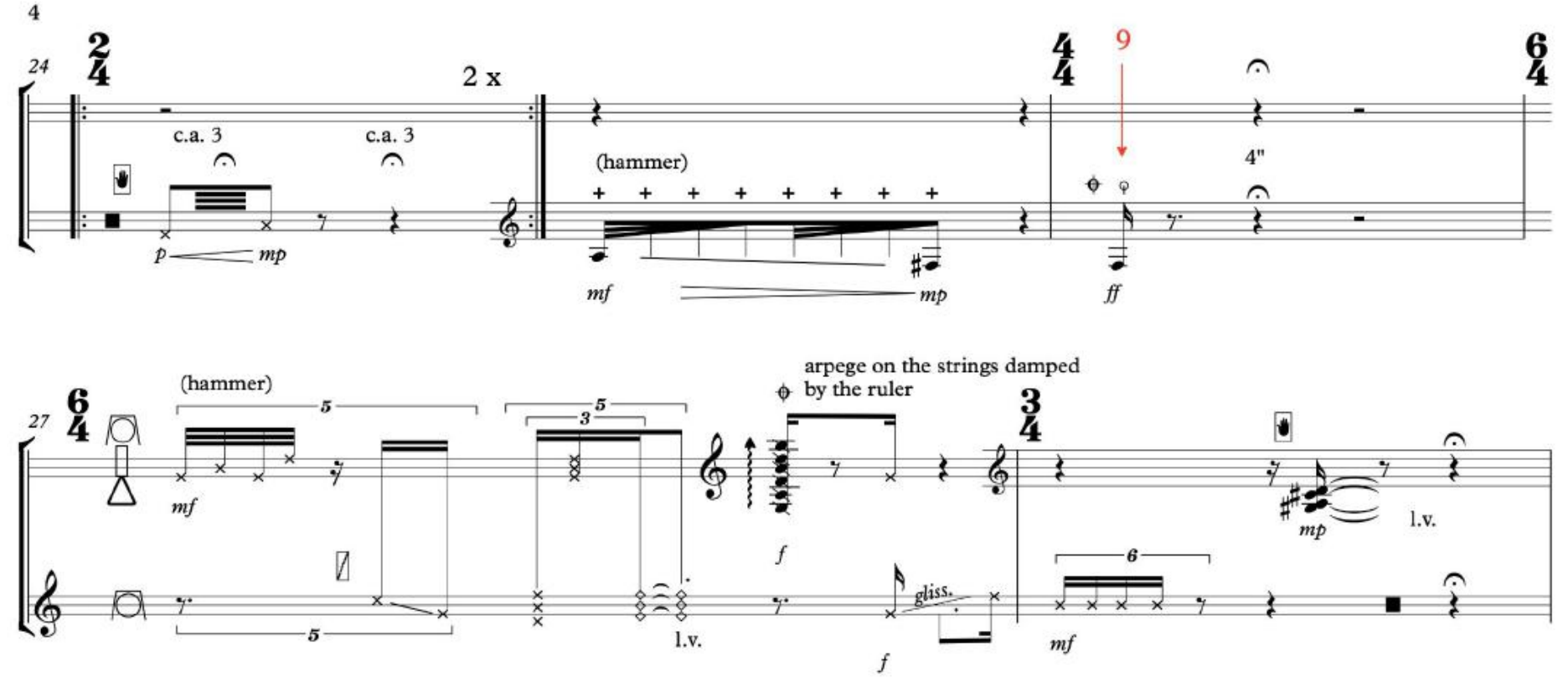

10

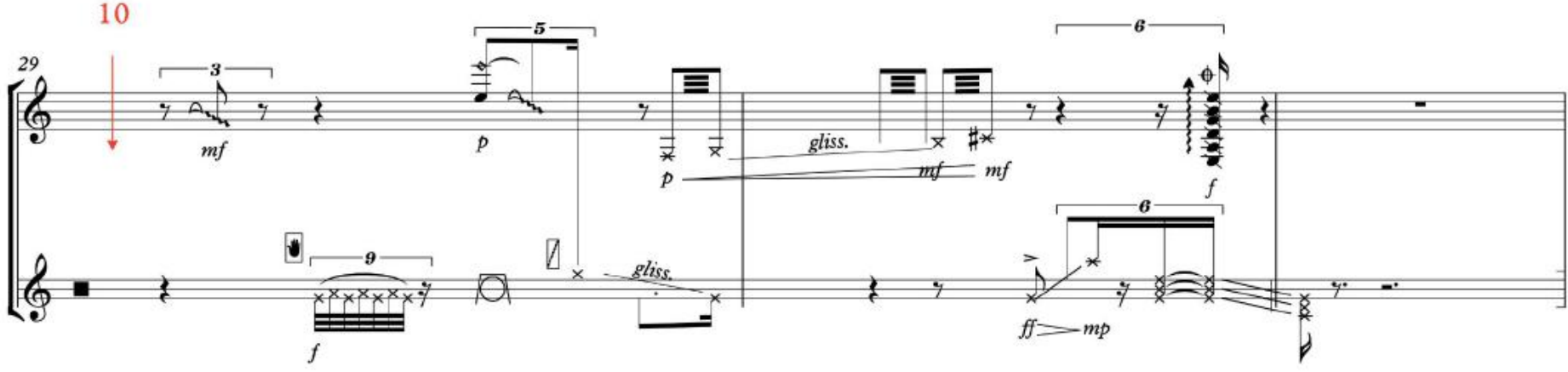

Turn on the add synthesis
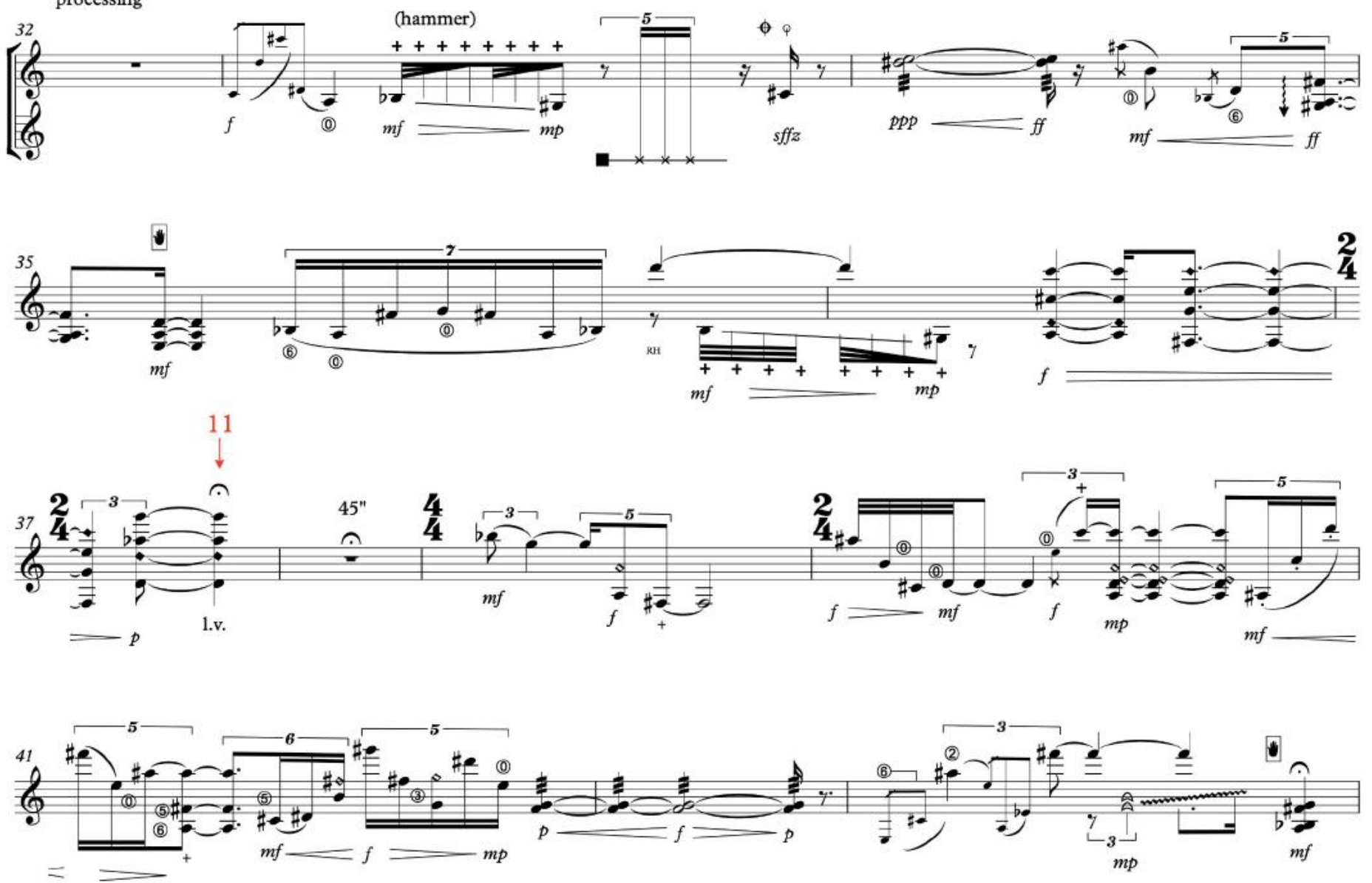


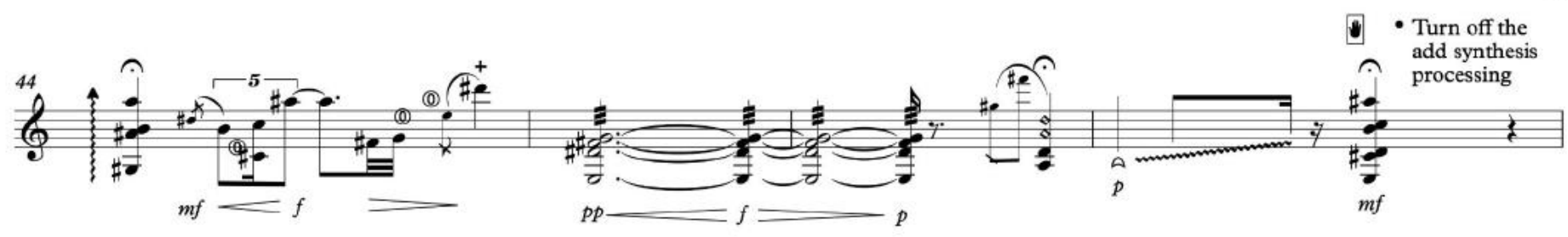

12

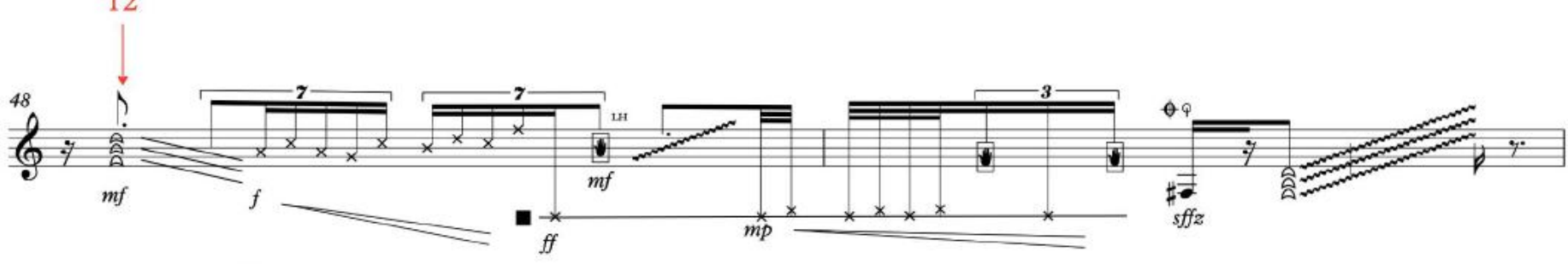

13

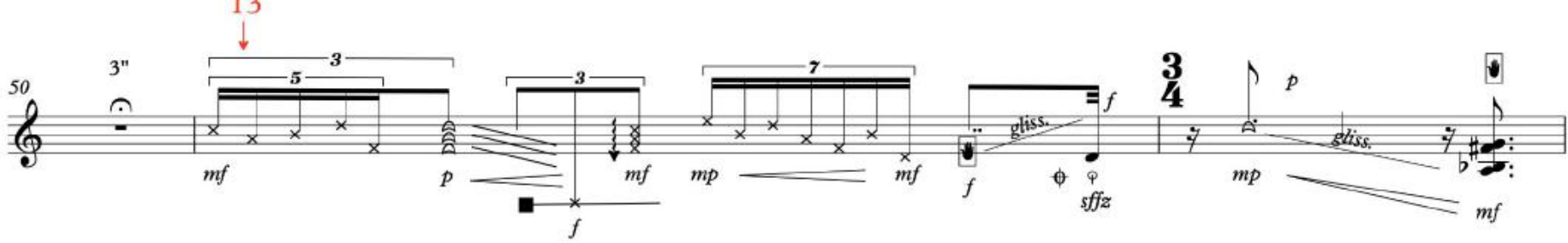

14

63

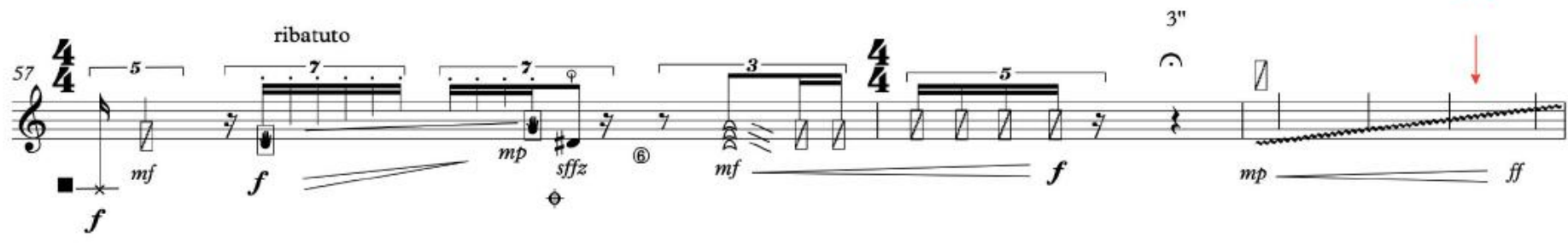

- Turn on the add synthesis processing
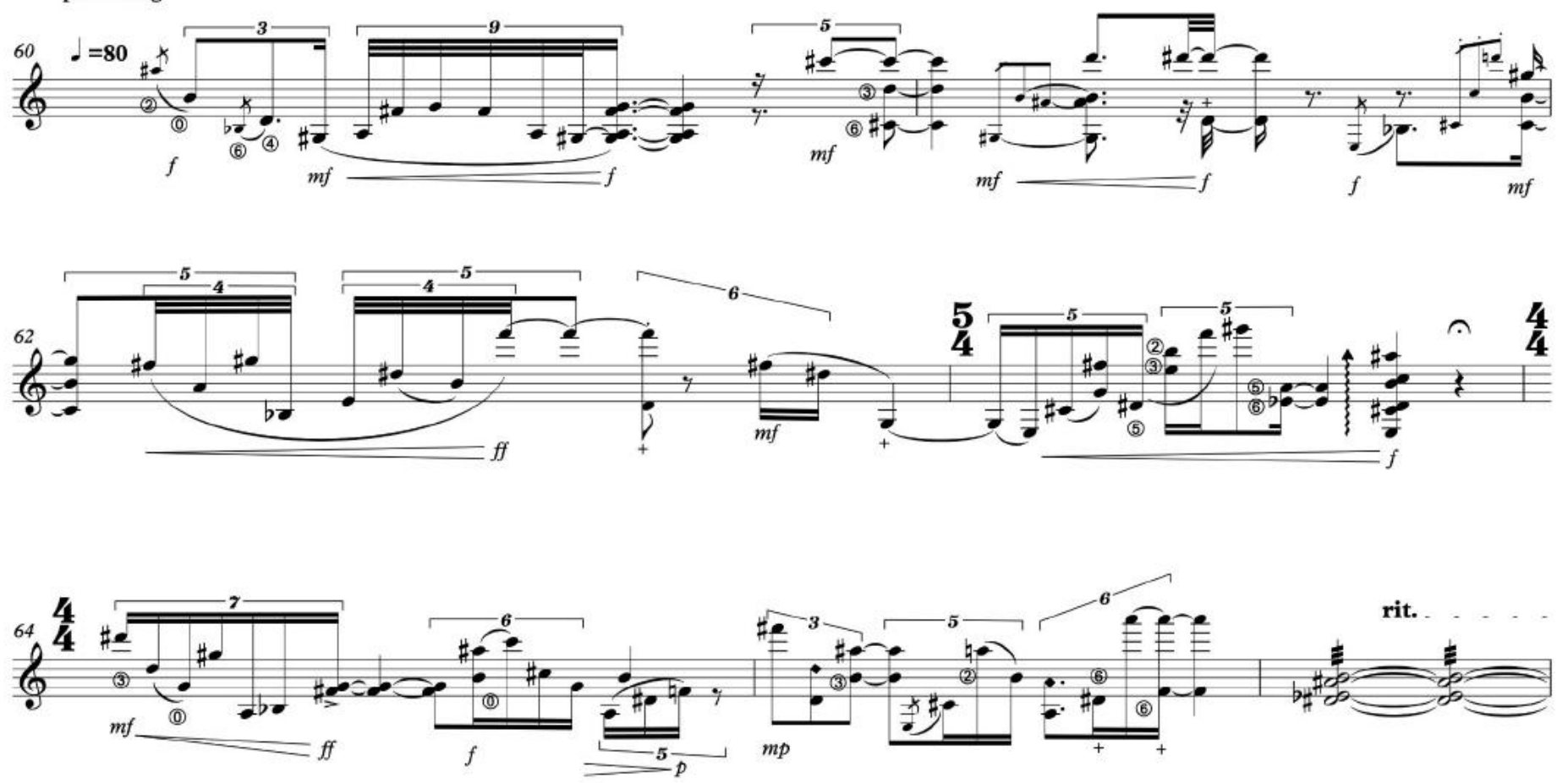

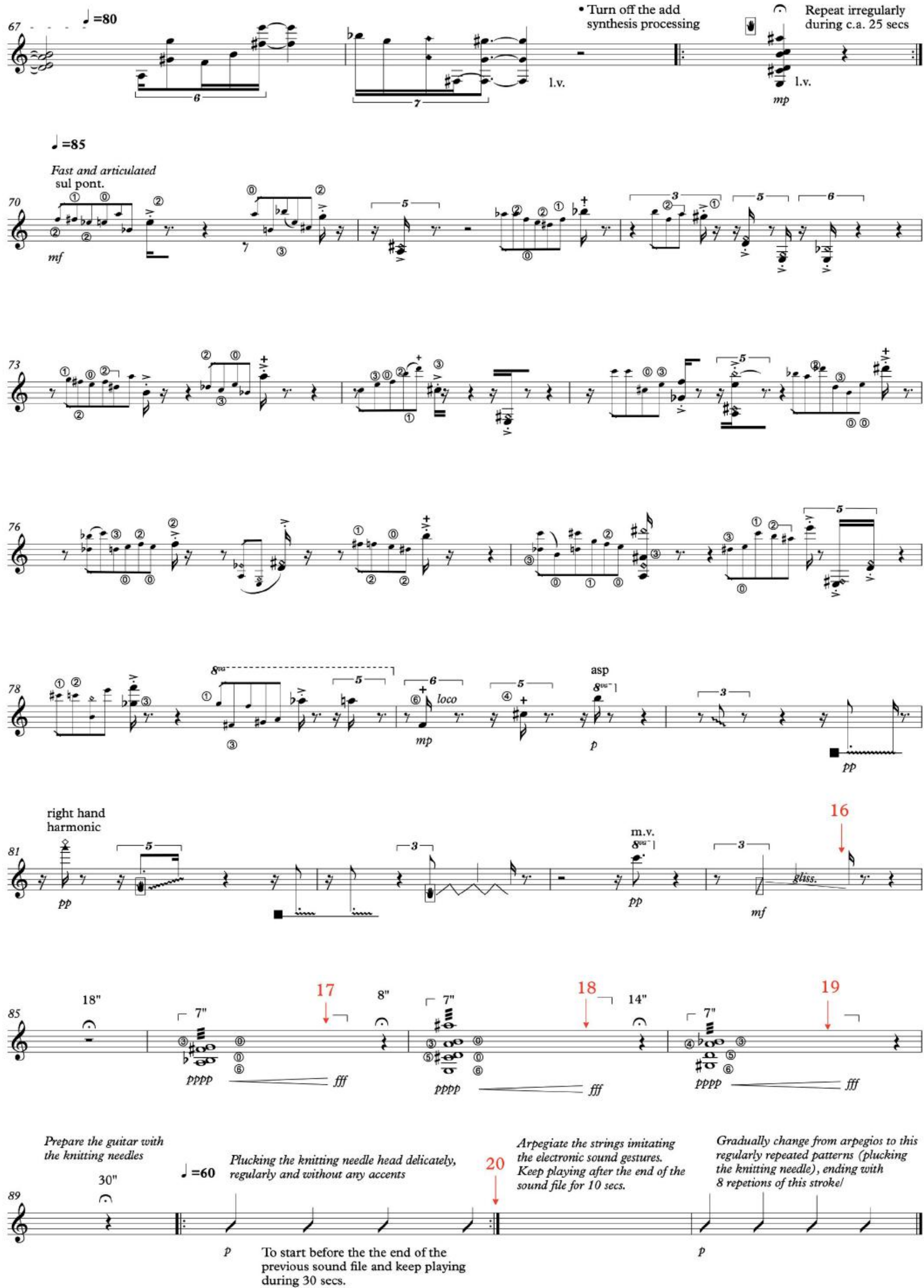